\title{
Book Review: Digital Demagogue: Authoritarian Capitalism in the Age of Trump and Twitter by Christian Fuchs
}

\author{
Ryan J. Phillips
}

Ryerson University, Toronto, Canada, Ryan.j.phillips@ryerson.ca

\begin{abstract}
Ryan J. Phillips reviews Christian Fuchs' Digital Demagogue: Authoritarian Capitalism in the Age of Trump and Twitter. Fuchs' latest work provides an excellent critical perspective on the global rise of right-wing populism and authoritarianism, and explores the specifics of Trump's brand of authoritarian ideology and its dissemination via social media platforms.
\end{abstract}

Keywords: Donald Trump, authoritarianism, capitalism, Twitter, critical theory

Christian Fuchs' Digital Demagogue: Authoritarian Capitalism in the Age of Trump and Twitter (2018) offers a thorough ideological critique of current US President Donald Trump's brand of authoritarianism. Contextualised within the contemporary rise of right-wing populism in other states such as Hungary, France, the Philippines, Austria, and Turkey, Fuchs identifies and critiques the ideological relationships between Trump, authoritarianism, capitalism, and new media - which Fuchs conceptualises as 'Trumpology'.

Like many of his previous works, Fuchs' theoretical and methodological foundations draw from the Frankfurt School of critical theory. Specifically, the analysis of Trump and authoritarian capitalism expand upon the models of authoritarianism previously developed by Theodor Adorno and Franz L. Neumann, respectively. Fuchs draws from these critical scholars in formulating a comprehensive model of authoritarianism, which is comprised of four dimensions: authoritarian leadership, friend/enemy schemes (or dichotomies), ethnocentrism and nationalism, and patriarchal militarism (53). Fuchs also outlines the various historical conceptualisations and current global manifestations of nationalism and authoritarianism, and systematically differentiates between fascism (the outright attempts to eliminate oppositional individuals and groups) and authoritarian capitalism (the extreme repression of oppositional individuals or groups) (58-59).

Fuchs' systematic identification and critical analysis of Trump's specific brand and methods of authoritarianism provide helpful insight into the ongoing and worsening problems of the post-2016 US. Additionally, Fuchs also notes the historical developments of neoliberalism that have led to the current crisis of authoritarian capitalism - drawing, again, from a historical materialist methodology. The author provides historicised comparative analyses of the political, economic, and cultural conditions that gave rise to Trump and other authoritarian movements such as Marine Le Pen in France, Brexit, and Hitler's brand of Nazi fascism. Though subtle differences between these examples and the Trump phenomenon exist, Fuchs effectively highlights the significant similarities between the fundamental elements of these rightwing authoritarian historical moments. For example, Fuchs examines data regarding voter support for these various causes, and finds significant similarities regarding voter 
demographics - Trump, Le Pen, Brexit, and Hitler were all strongly supported by manual labourers from rural areas with lower levels of education.

In order to explain this trend, the author argues that, under certain specific social and economic conditions, right-wing authoritarian movements can be successful in supplanting ideological appeals to national or racial unity in place of class antagonisms and economic anxieties, especially in cases wherein no viable left-wing alternative exists (44). Fuchs thus uses Trump's presidential campaign and early presidency as a case study of these issues, specifically focusing on the ways in which Trump uses social media to espouse right-wing authoritarian ideology. In terms of method, Fuchs employs critical discourse analysis in order to assess elements of authoritarian capitalism in an aggregated dataset of Trump's tweets on Twitter and, consistent with other instances of authoritarian movements, identifies a trend of appealing to friend/enemy schemes, ethno-nationalism, authoritarian leadership, and patriarchal militarism (in addition to a consistent narcissistic motif of possessive individualism).

One issue with Fuchs' analysis is the author's conceptualisation of authoritarian capitalism. Fuchs notes that authoritarian capitalism is "a capitalism that uses repressive state power in order to advance capitalist interests, which features a blurring of the boundaries between the state and big capital, state intervention into the economy in favour of big capital, law-and-order politics, armament and militarism, and a certain degree of repressive politics against immigrants, the political opposition and other constructed enemies" (58). This conception thus positions authoritarian capitalism as a political regime that represses citizens (especially minority citizens) while enacting laws and policies aimed at supporting large private corporations and wealthy individuals - effectively a more politically authoritarian version of neoliberalism.

However, this macro-level conceptualisation of authoritarian capitalism seems to ignore the inherently authoritarian qualities of capitalism itself. The nature of capitalism is such that it relies upon the exploitation of labour (i.e. the majority of citizens of any given state) in order to increase surplus-value and perpetuate rigid social, political, and economic hierarchies. As such, capitalism is by its very nature an authoritarian social structure, given that exploitation and repression of working citizens is a necessary component of its internal logic. In this sense, even the term 'authoritarian capitalism' seems a bit redundant. While true that the recent global rise of right-wing authoritarianism is in many ways different from fascism and other historical capitalist state systems (such as colonialism, neoliberalism, and so on), authoritarianism is still not a unique quality of the current historical moment of global capitalism.

A second (though significantly less problematic) issue with Fuchs' work is the author's prescriptive strategies for addressing the threats posed by Trump and other right-wing populists in the twenty-first century. Specifically, Fuchs suggests that media outlets either ignore Trump's antics and deny coverage of his outlandish behaviour thereby disallowing any further amplification of his ideological communications - or else engaging in satirical coverage of his and his administration's authoritarian regime. While satirical coverage of Trump (especially from a critical, socialist perspective, as Fuchs prescribes) could certainly be helpful in resisting against such a selfaggrandising and narcissistic political figure, ignoring Trump altogether could be a counterproductive tactic. Given the unprecedented severity of many laws and policies brought forth by Trump and his administration, a culture of news media that ignores such egregious attacks on democratic institutions and social norms risks further normalising such phenomena. Instead, news media ought to continue to critically cover Trump's actions and ideological communications, though also provide more balanced reporting that allocates appropriate time to covering counter-positions, resistance 
measures, historical context, and viable alternatives - a strategy only implicitly advocated by Fuchs (254-255).

Fuchs' most recent work provides a thorough analysis of Trump's ideology and the means by which that ideology is propagated and amplified through social media, especially through Twitter. While the author's conceptualisation of 'authoritarian capitalism' is somewhat theoretically problematic, it nonetheless provides a point of entry for ways to qualify and conceptualise the current historical moment of global capitalism. Additionally, while I disagree with some of Fuchs' prescriptive measures for addressing Trump's authoritarianism and ideological dissemination, the book does contribute in an insightful way to the ongoing intellectual and public discussion regarding methods of practical resistance. Overall, Fuchs' book is an exceptional work by a dedicated critical scholar, and ought to be read by any scholars, activists, or citizens interested in better understanding critical theory and the intersections of ideology, authoritarianism, Trump, and social media.

\section{About the Author}

Ryan J. Phillips

Ryan Phillips is a PhD Candidate in Ryerson University's Communication and Culture program, where his research focuses on media politics and economics, promotional cultures, and rhetoric. Specifically, his work focuses on the promotional culture of alternative foods, as well as the political economy of sports broadcasting in Canada. 